\title{
The Impact of Using Many Jargon Words, while Communicating with the Organization Employees
}

\author{
Ngueviuta Patoko, Rashad Yazdanifard \\ Centre of Post Graduates Studies, Limkokwing University of Creative Technology, Cyberjaya, Malaysia \\ Email: nspatoko@yahoo.com, rashadyazdanifard@yahoo.com
}

Received 6 March 2014; revised 5 April 2014; accepted 2 May 2014

Copyright $@ 2014$ by authors and Scientific Research Publishing Inc.

This work is licensed under the Creative Commons Attribution International License (CC BY).

http://creativecommons.org/licenses/by/4.0/

(c) (i) Open Access

\section{Abstract}

For an organization in order to ensure that it is running smoothly, and its goals are being met to the best of the organization ability, there must be a solid communication between the management and employees involved. Therefore, communication is supposed to be effective and efficient when it is being used in the organization. Management should ensure that there are less jargon words that are being used in the daily communication with the employees in order to avoid miscommunication that may be detrimental to organizational success. This is also to make sure that communication is still serving its purpose in the organization, of information or ideas sharing. In situations where insufficient communication occurs, it tends to hamper the effective and efficient communication, as a result it leads employees to being demoralized and having a high employee turnover, relationships between employees and employers being tarnished, wastage of organizational resources and as well as negatively impact the organization productivity. Employees should be treated with care as they form a very integral component of the organization. In this paper, the impact of using many jargon words, while communicating with the organization employees is being investigated.

\section{Keywords}

Jargon, Employees, Organizations, Impact, Communication

\section{Introduction}

[1] states that communication can be defined as a process that focuses on how employees and managers use information such as ideas, thoughts and feelings to each other to generate meanings within and outside the or- 
ganization. This process can take place in a form of a verbal and nonverbal communication.

Communication is essential to many if not all organizations, therefore organizational management and collaboration processes simply cannot take place without effective communication. Unfortunately, desired communication is not always easily achieved in these institutions. This is as a result of diverse cultures within organizations as well as different ways in which organization managers convey or communicate to their employees, such communication leads to conflicts and misunderstandings [2]. This paper investigates the impact of using many jargon words, while communicating with the organization employees.

Firstly, some previous findings on the use of jargon words are examined. The use of jargon's is been examined mainly on how it affect the employees. Additionally, the paper will be looking at how the ineffective communication caused by the use of many jargon words by managers on employees affect the entire organization productivity, and its profit margin. The paper proceeds with a brief discussion on a chosen topic. And finally, conclusion is provided to summarize the ideas of the paper.

\section{Daily Communication in the Organization}

[3] define organizational communication as all communication that is aimed at enhancing the status as well as the satisfaction within the organization. [4] stated that organizations will not exist if there is no appropriate communication, as a result, the top management will find it very difficult to be able to receive information from the lower management and vice versa. In the same vain, the authors went on to state that supervisors will find it hard to be able to give appropriate instructions to their subordinates, as a result, the coordination of work will be impossible and the organization will inevitably collapse due to that. [5] mentioned the importance of having a jargon free communication environment that will facilitate a timely exchange of appropriate information and a rapid adjustment of the messages exchanged between the managers and the employees, so that misunderstandings can be avoided beforehand. [6] on the other hand, pointed out that miscommunication is a negative act, and it will inevitably provoke undesirable consequences for the organization. Further, managers should be closely observed on how they might perceive themselves, and how they perceive their employees as well as their relationships with employees in the organization, and the jargons when addressing the junior staff which might prove detrimental to good communication. [7] mentioned the reciprocity and participative learning that involves managers and employees is effective since managers will be urged to communicate to employees in the manner and language easily understandable by the employees, which definitely have less jargons.

\section{Method}

This study philosophically falls under interpretivism class, the under taken research approach is explanatory and the research strategy is literature survey. Consequently this study used secondary data and qualitative analysis techniques. International journals as well as proceedings are dug up through international well-recognized databases like emerald. Papers were collected over a two-week period and reviewed jointly with authors over another two-week period. A couple of discussions around the design and the objective of the study were done with a senior lecturer in order to improve the flow of study. The arrangement of literature survey was planned to be started with reviewing the term jargon from different perspectives and then how the use of jargon words affect the daily communication with employees in the organizations.

\section{Jargon}

Is the language, especially the vocabulary, peculiar to a particular trade, profession, or group such as doctors and engineers in their respective professions. A jargon can also be a meaningless talk or writing that one does not understand and it can be characterized by unfamiliar vocabulary [8]. Furthermore, the use of jargon words can be defined in knowledge stickiness, in the sense that knowledge stickiness entails a process that is difficult to transfer knowledge, the difficultly attributed to the way the information is encoded, as well as the characteristics of the employees or managers, such as their skills and experiences with a particular type of knowledge that need to be transferred [9]. Jargon can be said as a negative term of various kinds such as the use of slang [10]. Finally, [11] define it as a language characteristic used by a certain group. In this paper, the jargon term will be used as an unfamiliar vocabulary being used by managers on the employees. 


\section{Employees Treatment in the Organization}

[12] argued that creating a sense of ownership for the employees has the potential to align the employee's objectives and aspirations with organizations strategies, further giving employees a greater sense of belongingness thus increasing their commitment to the organization. Further, the authors highlighted that in order to achieve this, it is important that management recognize employees as part and parcel of the organization and adopt a culture of sharing information and encourage the employees to participate actively in decision making as well as effective communication at all levels within the organization. Furthermore, employees should be valued and be treated like the organization customers. Additionally, employees should be trained and motivated, so that they do not just feel like they belong to the organization, but that they are part of the organization [13].

[14] added that when organization managers are making statements with regard to employees in order to preserve their value, managers should be aware of not using jargon's or words that might confuse the employees and cause unnecessary implications. The author, further concluded by stating that management should choose words wisely and phrases that clearly reflects how the organization intends to act toward its employees. [15] mentioned that in an effort to ease the communication barriers created in the organization because of the use of many jargon words, organizations should facilitate informal communication in order to allow the exchange of appropriate information among the employees. [16] additionally, suggested that informally communicated information is at times more accurate and effective than the information communicated through formal channels. [17] shared the same sentiments by stating that communication has a huge positive impact on employees when it has been channeled informally, the authors further mentioned that managers should consider communicating in different languages, which is suitable to the different educational levels of their employees.

\section{Organizations Actions towards the Employees}

Since organizations are operating in increasingly ever-changing environments and mostly characterized by speedy change and uncertainty, as a result organization managers tends to make decisions in uncertainly as well, because they might not be aware of how affectively information should be communicated to the employees [18].

[19] stated that managers who give messages that have few or no jargon's resulted in positive attitudes of realism and trust among fellow employees as well as with their employers. Organizations should take a unified approach, whereby the management can categorize the employees according to the language skills they possess in order to be aware of what language standard they should use to communicate with them [20]. [21] suggested organization training on its employees should be structured on clear understanding of the employee's know-how as well as their skills. [22] mentioned that communication "content" has taken a new shift to "behavior" therefore the employees interpretation of communication from the managers now depends not only on "what" is said but also on "how" it is said. [23] cited that organizational training on employees should be tailored firstly for the employees benefit, and then for the organization as a whole. Consequently, such training must have a few or no jargons so that knowledge and skills can be sufficiently transferred to the employees, and the impact of such training outcome can be observed on the organizational productivity. [24] finally, said that managers must find a common language to be used in multilingual organizations; as such this language must have no jargons, since jargons can be used to hide certain facts about the organization especially to the new employees who are not familiar with corporate terms. Moreover, this particular language must be easily acceptable and embraced by the entire organization work force.

\section{Impact on the Employees Productivity}

A conducive workplace along with a good job design and quality of supervision can be key motivational forces for workers in an organization, although firms at times operate under severe resources constraints. Furthermore, as far as staff training is concerned, such outcome could have a major impact on an organizations survival as employees on-the-job learning act as a major trigger to improved employee performance since employees become motivated. Moreover, there seems to be an immediate need for organization managers to train their staff in simple language and avoid jargon words that may hamper the training process. This will help the employee regain motivation, which has been lost as a result of poor financial rewards [25]. In support, [26] mentioned that managers in organizations should undertake performance management, whereby a working environment is created to ensure that the employees can perform to the best of their abilities. This whole performance manage- 
ment system takes place when employees jobs are well defined and the expectations are clearly communicated in a plain understandable language were the jargons have been omitted. [27] shared the same sentiments, by mentioning that even though managers are driven by performance, they should ensure that their intentions are well communicated to the employees in an unambiguous manner so that it will impact employees positively. [28] found that, the impact on organization manager's characteristics as well as their leadership and knowledge skills may affect the employee's prospects, and their needs. Therefore, it is pivotal for managers to be down to the ground and use less jargon in their daily communication with the employees. [29] added that, when organization managers lack adequate communication skills, communicating to employees about relevant organization issues becomes more difficult. Employees will have difficulty in understanding whatever is being communicated to them from the top management, as a result, they will tend to feel greater job insecurity and distrust the employers as well as the entire organization. [30] suggest that organizational communication ambiguities as well as their role vagueness are the most negative influencing factors for employee's job satisfaction.

\section{Discussion}

Top management are mostly the highest educated people, comparing to the ordinary low level employees in the organization as a result they might willingly or un-willingly use terms or jargons that the employees are not familiar with in the communication process. Additionally, managers should always either intentionally or unintentionally make a valuation of their employee's intellect and level of expertise in order to always be aware on what level the information should be communicated to them. If managers are not aware of this, they risk isolating or even irritating the employees.

Although, it is inevitable for managers not to use a new word, a jargon or phrase whenever they are to communicate with the employees, because managers at times fail to realize that the terms/jargons they know well may prove to be difficult or meaningless to their employees. Therefore, managers should avoid using a lot of jargons in their daily statements alternatively mangers should try to substitute such jargons with everyday language if possible. Managers might want to sound smarter and impress their employees but this type of language does not facilitate communication, instead it hinders it. In some scenarios, managers may even intentionally hinder communication in the organization by using many jargons to avoid hard questions or hide failure from the employees.

The use of jargons by managers can greatly impact the thinking as well as the actions and morals of the employees, since managers have a big influence on their employees. Furthermore, the use of jargons is likely to be interpreted by employees as implying a particular negative attitude on the part of the manager, as a result Jargon words might cause miscommunication between managers and employees and the entire organization might suffer in terms of productivity ultimately, and its profit margin. It is worth noting that, when the organization's employees feel that they are being looked down by their managers as a result of the different classes they belong to, they will tend to lose their sense of belonging and faith in the organization hence, they will become demoralized. As a result, demoralized employees will not properly execute their organization's obligations.

Finally, organizations should ensure that all necessary daily communication is being carried out in the language simple enough for employees to fully grasp.

\section{Conclusions}

Communication is a complex and also frequently a difficult process for both the managers and the employees. Hence barriers from both sides of the communication process often deflect the real meaning of the intended message and hinder clear, open and rewarding communication in the organization.

The paper has examined the impact of using many jargon words, while communicating with the organization employees. The investigations have showed that many jargon words are being used in daily communication, but it becomes worthless when it gets in a way of communicating ideas or information as a result, it tends to negatively impact the effective and efficient communication in the organization.

Furthermore, the use of jargons makes employees feel irritated and left out, hence they end up misunderstanding whatever has been communicated to them and that affect individual productivity as well as the organization's productivity and its profit margin. Employees are human with egos and pride, therefore they must be handled with good care as they form a big part of the organization's wellbeing. Moreover, when managers use jargon words to employees, and if they cannot clearly explain it in an ordinary language, a special term that every- 
one within the organization can clearly understand must be used instead as this is essential for good communication and for building a good relationship between managers and employees.

This paper is not encouraging managers to leave out necessary technical terms when they are communicating with their employees because most of such terms cannot be easily simplified for employee's sake.

Finally, employees are humans as such they may face hesitation, although they might accept that they are unaware of certain terms. Because they might chose to keep quiet and not ask probing questions as they are afraid that the management might feel they do not have the basic knowledge. Normally, employees especially the junior ones might feel uneasy to ask questions therefore it is the management responsibility to maintain a conducive communication environment to enhance effective communication in the organization.

\section{Acknowledgements}

I would like to express my earnest gratitude and appreciation to Limkokwing University of Creative Technology for giving me the opportunity to complete this publication. In addition, I would also like to thank the reviewers for their cautious reading and constructive comments. A special thanks to Mr. M. F. T. Mbuti and Mr. U. S. F. Muhenje for comprehensively proof-reading my work as well as to my senior lecturer, Dr. R. Yazdanifard, whose help, stimulating suggestions and encouragement, helped me successfully complete this publication.

\section{References}

[1] (2014) What Is Communication? http://www.natcom.org/discipline/

[2] Lauring, J. and Selmer, J. (2012) Positive Dissimilarity Attitudes in Multicultural Organizations: The Role of Language Diversity and Communication Frequency, Corporate Communications. An International Journal, 17, $156-172$. http://dx.doi.org/10.1108/13563281211220292

[3] Elving, W., van Ruler, B., Goodman, M. and Genest, C. (2012) Communication Management in the Netherlands: Trends, Developments, and Benchmark with US Study. Journal of Communication Management, 16, 112-132. http://dx.doi.org/10.1108/13632541211217551

[4] Awad, T.A. and Alhashemi, S.E. (2012) Assessing the Effect of Interpersonal Communications on Employees Commitment and Satisfaction. International Journal of Islamic and Middle Eastern Finance and Management, 5, 134-156. http://dx.doi.org/10.1108/17538391211233425

[5] Friedman, K. (2011) You're on! How Strong Communication Skills Help Leaders Succeed. Business Strategy Series, 12, 308-314. http://dx.doi.org/10.1108/17515631111185941

[6] Petelin, R. (2010) Considering Plain Language: Issues and Initiatives, Corporate Communications. An International Journal, 15, 205-216. http://dx.doi.org/10.1108/13563281011037964

[7] Armson, G. and Whiteley, A. (2010) Employees and Managers’ Accounts of Interactive Workplace Learning: A Grounded Theory of “Complex Integrative Learning”. Journal of Workplace Learning, 22, 409-427. http://dx.doi.org/10.1108/13665621011071091

[8] Dictionary.com. (2014) The Definition of Jargon. http://dictionary.reference.com/browse/jargon

[9] Sheng, M.L. and Chang, S.Y. (2013) Knowledge Barriers, Knowledge Transfer, and Innovation Competitive Advantage in Healthcare Settings. Management Decision, 51, 461-478. http://dx.doi.org/10.1108/00251741311309607

[10] Nordquist, R. (2014) Jargon—Definition and Examples of Jargon. http://grammar.about.com/od/il/g/jargonterm.htm

[11] Jargon: Wiktionary (2014) http://en.wiktionary.org/wiki/jargon

[12] McCarthy, D., Reeves, E. and Turner, T. (2010) Can Employee Share-Ownership Improve Employee Attitudes and Behavior? Employee Relations, 32, 382-395. http://dx.doi.org/10.1108/01425451011051604

[13] Bowers, M.R. and Martin, C.L. (2007) Trading Places Redux: Employees as Customers, Customers as Employees. Journal of Services Marketing, 21, 88-98. http://dx.doi.org/10.1108/08876040710737859

[14] Schraeder, M. (2009) Incongruence in the Value of Employees: Organizational Actions Speak Louder than Words. Development and Learning in Organization, 23, 4-5. http://dx.doi.org/10.1108/14777280910933702

[15] Jaitli, R. and Hua, Y. (2013) Measuring Sense of Belonging among Employees Working at a Corporate Campus: Implication for Workplace Planning and Management. Journal of Corporate Real Estate, 15, 117-135. http://dx.doi.org/10.1108/JCRE-04-2012-0005

[16] Fay, M.J. (2011) Informal Communication of Co-Workers: A Thematic Analysis of Messages. Qualitative Research in Organizations and Management: An International Journal, 6, 212-229. http://dx.doi.org/10.1108/17465641111188394 
[17] Holtzhausen, L. and Fourie, L. (2008) Communicating to a Diverse Workforce: Employees’ Perceptions of Symbolic Corporate Identity Elements. Corporate Communications: An International Journal, 13, 80-94. http://dx.doi.org/10.1108/13563280810848210

[18] Nothhaft, W. (2010) Communication Management as a Second-Order Management Function: Roles and Functions of the Communication Executive--Results from a Shadowing Study. Journal of Communication Management, 14, 127140. http://dx.doi.org./10.1108/13632541011034583

[19] Mazzei, A. and Ravazzani, S. (2011) Manager-Employee Communication during a Crisis: The Missing Link. Corporate Communications: An International Journal, 16, 243-254. http://dx.doi.org/10.1108/13563281111156899

[20] Hopp, A. (2013) Empowered Talent Begins with Communication: Virtual Classrooms, Mobile and E-Learning Are Perfect Blend for Language Learning. Human Resource Management International Digest, 21, 30-32. http://dx.doi.org/10.1108/HRMID-08-2013-0066

[21] Aboelmaged, M.G. and El Subbaugh, S.M. (2012) Factors Influencing Perceived Productivity of Egyptian Teleworkers: An Empirical Study. Measuring Business Excellence, 16, 3-22. http://dx.doi.org/10.1108/13683041211230285

[22] Dasgupta, S.A., Suar, D. and Singh, S. (2013) Impact of Managerial Communication Styles on Employees’ Attitudes and Behaviours. Employee Relations, 35, 173-199. http://dx.doi.org/10.1108/01425451311287862

[23] Dirani, K. (2012) Professional Training as a Strategy for Staff Development: A Study in Training Transfer in the Lebanese Context. European Journal of Training and Development, 36, 158-178. http://dx.doi.org/10.1108/03090591211204698

[24] Tange, H. and Lauring, J. (2009) Language Management and Social Interaction within the Multilingual Workplace. Journal of Communication Management, 13, 218-232. http://dx.doi.org/10.1108/13632540910976671

[25] Panagiotakopoulos, A. (2013) The Impact of Employee Learning on Staff Motivation in Greek Small Firms: The Employees' Perspective. Developing and Learning in Organization, 27, 13-15. http://dx.doi.org/10.1108/14777281311302030

[26] Sahoo, C.K. and Mishra, S. (2012) Performance Management Benefits Organizations and Their Employees. Human Resource Management International Digest, 20, 3-5. http://dx.doi.org/10.1108/09670731211260771

[27] de Waal, A.A. (2007) Is Performance Management Applicable in Developing Countries. Performance Management? The Case of a Tanzanian College. International Journal of Emerging Markets, 2, 69-83. http://dx.doi.org/10.1108/17468800710718903

[28] Esteve, A.E. and Sanches A.M. (2012) Guest Editorial: Creativity and Innovation in the Firm: Managerial Antecedents and Effects on Employees. International Journal of Manpower, 33, 344-348. http://dx.doi.org/10.1108/01437721211243796

[29] Salem, P. (2008) The Seven Communication Reasons Organizations Do Not Change. Corporate Communications: An International Journal, 13, 333-348. http://dx.doi.org/10.1108/13563280810893698

[30] Chung, T.L., Rutherford. B. and Park, J. (2012) Understanding Multifaceted Job Satisfaction of Retail Employees. International Journal of Retail \& Distribution Management, 40, 699-716. http://dx.doi.org/10.1108/09590551211255974 
Scientific Research Publishing (SCIRP) is one of the largest Open Access journal publishers. It is currently publishing more than 200 open access, online, peer-reviewed journals covering a wide range of academic disciplines. SCIRP serves the worldwide academic communities and contributes to the progress and application of science with its publication.

Other selected journals from SCIRP are listed as below. Submit your manuscript to us via either submit@scirp.org or Online Submission Portal.
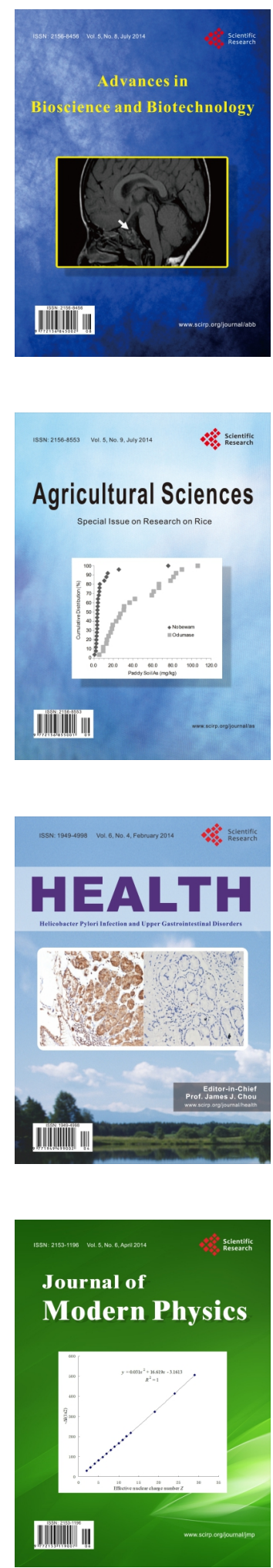
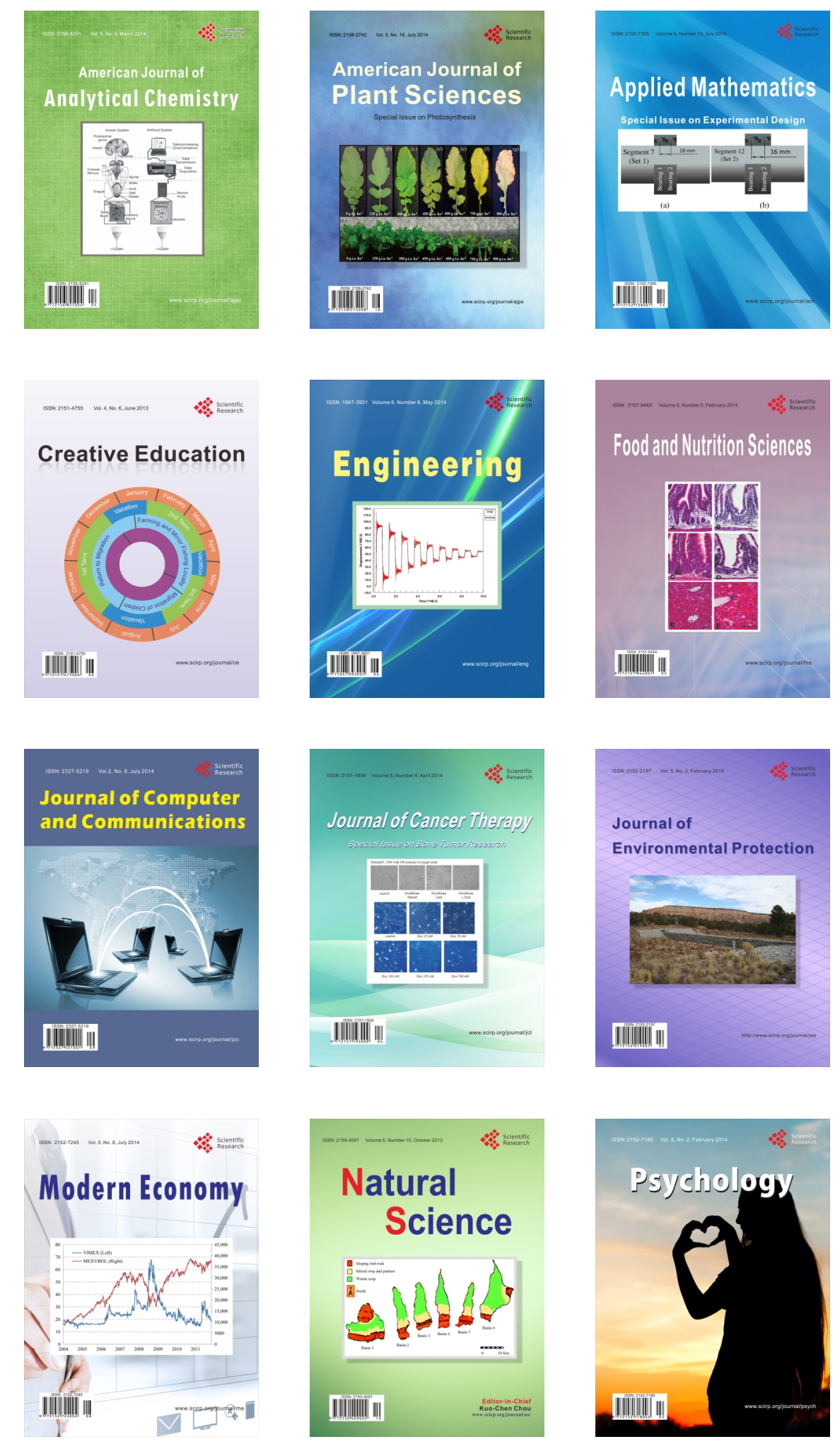